\title{
QTLs for early vigor of tropical maize
}

\section{Journal Article}

\section{Author(s):}

Trachsel, S.; Messmer, R.; Stamp, P.; Ruta, N.; Hund, Andreas (D)

Publication date:

2010

Permanent link:

https://doi.org/10.3929/ethz-b-000017420

\section{Rights / license:}

In Copyright - Non-Commercial Use Permitted

\section{Originally published in:}

Molecular Breeding 25(1), https://doi.org/10.1007/s11032-009-9310-y 


\title{
QTLs for early vigor of tropical maize
}

\author{
S. Trachsel $\cdot$ R. Messmer $\cdot$ P. Stamp . \\ N. Ruta $\cdot$ A. Hund
}

Received: 6 February 2009/Accepted: 2 July 2009/Published online: 26 July 2009

(C) Springer Science+Business Media B.V. 2009

\begin{abstract}
A strong photosynthetic performance and rapid leaf development, are important indicators of vigorous early growth. The aim of this study was to (1) evaluate the tropical maize (Zea mays L.) inbred lines CML444 and SC-Malawi for their photosynthetic performance at different growth stages and (2) assess quantitative trait loci (QTL) of photosynthesisrelated traits in their 236 recombinant inbred lines at the heterotrophic growth stage. CML444 had a higher leaf chlorophyll (SPAD) content than SC-Malawi. Ten QTLs were found for the quantum efficiency of photosystem II ( $\Phi_{\mathrm{PSII}}$; four), SPAD (three) and the specific leaf area (SLA; three). The relevance of seedling QTLs for $\Phi_{\text {PSII }}$, SPAD and SLA for yield formation is emphasized by seven collocations (bins 5.01, 7.03, 8.05) with QTLs for kernel number and grain yield under field conditions. QTLs for SPAD at the V2 and at the reproductive stage did not collocate, indicating differences in the genetic control of SPAD at different growth stages. Knowing which loci affect SLA, SPAD and $\Phi_{\mathrm{PSII}}$ simultaneously and which do not will help to optimize light harvest by the canopy.
\end{abstract}

S. Trachsel $(\bowtie) \cdot$ R. Messmer · P. Stamp ·

N. Ruta $\cdot$ A. Hund

Institute of Plant Science, ETH Zurich, Universitaetstr. 2, 8092 Zurich, Switzerland

e-mail: sat9@psu.edu; samuel.trachsel@ipw.agrl.ethz.ch
Keywords QTL · Early vigor · Photosynthesis · Leaf chlorophyll content - SPAD .

Zea mays L.

\section{Introduction}

Strong photosynthetic performance and early canopy closure, i.e., rapid leaf development, are the two most important target traits for vigorous early growth. There is an optimization function between the maximization of the leaf area on the one hand and photosynthetic performance on the other.

Photosynthesis, measured as the carbon exchange rate (CER), depends on the amount of photons absorbed by the chlorophyll of the leaves and on how efficient photons are used for carbon assimilation. The leaf chlorophyll content can be measured with a chlorophyll meter (SPAD; Xu et al. 2000), since the SPAD values explain $82 \%$ of the variation in the leaf chlorophyll content. The leaf chlorophyll content itself is not indicative of the functioning of the photosynthetic apparatus. While it provides information about the number of nitrogen stored in the leaf (Piekielek and Fox 1992) and the amount of photons captured (Earl and Tollenaar 1997), it does not provide information about how efficient they are used for carbon fixation. This information can be gained, by measuring the CER, or by taking the quantum efficiency of photosystem II ( $\Phi_{\mathrm{PSII}}$; Genty et al. 1989) 
as a proxy measure. $\Phi_{\mathrm{PSII}}$ describes the proportion of light absorbed by chlorophyll associated with photosystem II, which is used for photochemistry given that there are no alternative electron sinks, such as photorespiration.

The gross assimilation rate on a plant level may also be increased by maximizing the leaf area. As reported by Richards (2000) the leaf area can increase without incurring additional costs by decreasing the amount of photosynthetic machinery per unit leaf area (Richards 2000). This in turn increases the leaf area per unit weight, measured as the specific leaf area (SLA). If the gain in assimilates due to the increase in leaf area is larger than the decrease in assimilates due to a decrease in the amount of photosynthetic machinery, the net assimilation rate increases. SLA was suggested to be suitable for selecting plants with high early vigor (Rebetzke et al. 2004); a high SLA allows the plant to close the leaf canopy at minimal carbon expenses. Thus, when rapid canopy closure improves the water use efficiency, as suggested for small-grain cereals (Richards et al. 2002), the maximization of leaf area by increasing the SLA, may be important. However, Wright and Hammer (1994) demonstrated a negative relationship between SLA and the transpiration efficiency of peanut. Furthermore, a high SLA would result in greater water loss after canopy closure due to the larger leaf area exposed to ambient air and lower transpiration efficiency (Sheshshayee et al. 2006). Therefore, a decline in SLA, as observed for temperate cereals (Rawson et al. 1987), may be an important mechanism of adaptation to drought after canopy closure. For example, a small SLA is an indicator of drought tolerance in grass species (Triticum aestivum and Tragus racemosus), reflected in a more xeromorphic leaf anatomy for the drought-tolerant $T$. aestivum when the leaf developed under drought (Kalapos et al. 1996).

The four parameters leaf area, SLA (determining leaf area and the density of photosynthetic machinery), SPAD (determining the amount of photons intercepted by leaves) and $\Phi_{\text {PSII }}$ (determining the efficiency of the photosynthetic machinery) can be used to differentiate among genotypes for early vigor. The influence of these parameters on plant performance depends mainly on the target environment and the developmental stage. For example, under chilling conditions of about $15^{\circ} \mathrm{C}$ during early plant development the maintenance of a high photosynthetic performance is of great importance. Accordingly, $\Phi_{\text {PSII }}$ and SPAD are routinely used to assess the photosynthetic performance of maize seedlings at low temperature (Fracheboud et al. 2002, 2004; Hund et al. 2004, 2005, 2007; Jompuk et al. 2005). The leaf chlorophyll content is known to be affected by drought in many crops including sorghum (Thomas and Howarth 2000) and wheat (Sarker et al. 1999). Arunyanark et al. (2008) therefore suggested SPAD as a suitable tool for the rapid assessment of the photosynthetic machinery for indirect selection towards drought tolerance in the field. After flowering, the maintenance of leaf chlorophyll content and photosynthetic activity at high levels is indispensable for yield formation. The allocation of photosynthates to the kernel after flowering is largely accountable for kernel set and ovule abortion (Thomas and Howarth 2000). Furthermore, photosynthetic activity influences kernel weight and overall grain yield (Wang et al. 1999). The leaf chlorophyll content affects staygreen towards the end of the cropping season and thereby determines the duration of grain filling and grain yield (Paponov et al. 2005; Wang et al. 1999).

The genetic control of the four parameters leaf area, SLA, SPAD and $\Phi_{\text {PSII }}$ and their interrelations are not well understood. However, there are some indications of pleiotropic effects among these traits, indicating that more must be learned if the light harvest by the canopy is to be optimized. For example, pleiotropic effects were found based on the collocations between quantitative trait loci (QTLs) for SLA, SPAD and $\Phi_{\text {PSII }}$ (Hund et al. 2005). SPAD and CER are negatively correlated with SLA (Hund et al. 2005) as a larger photosynthetic machinery per unit leaf area entail a more structured and heavier leaf. However, Hund et al. (2005) did not find evidence that selection for a high photosynthetic performance under low temperatures led to coselection for a constitutively low SLA, which might result in low productivity.

In order to predict early vigor and the resulting performance at the reproductive stage the genetic basis must be known for traits related to photosynthesis. This evaluation could be carried out most efficiently at the early seedling stage. However, trait values measured at that stage may be related to seed biomass (Pommel 1990), thus potentially biasing the relationship between early vigor of photosynthetic traits at early and late developmental stages. We 
therefore tested the target material in this study at the heterotrophic and the early autotrophic growth stages and weighed the seeds.

The objectives were to: (1) compare seedlings at the heterotrophic two-leaf-stage (V2) to those at the autotrophic five-leaf-stage (V5) for the consistency of traits related to photosynthesis, (2) identify QTLs for photosynthesis-related traits at the seedling stage and (3) compare them with QTLs identified under field conditions at the reproductive stage (Messmer 2006). The parental lines CML444 and SC-Malawi were used to compare plants measured at the $\mathrm{V} 2$ and at the V5 stage, while their RIL population was subsequently used for a QTL mapping study.

\section{Materials and methods}

Evaluation of the parents CML444 and SC-Malawi

The seeds of two tropical maize inbred lines and 236 recombinant inbred lines (RILs, F7:S6) were obtained from CIMMYT. The parental line CML444 has the characteristics of a drought tolerant maize ideotype as described by Ribaut et al. (2008). It has been developed at CIMMYT during the 1990s, by selecting for high yield under drought stress at flowering. SCMalawi is an old inbred line developed in Zimbabwe in the 1960s. Compared to CML444, SC-Malawi has a low yield under stress and non-stress conditions (Messmer 2006). In two experiments prior to the QTL study CML444 and SC-Malawi were tested in growth pouches (unpublished data) and in growth columns (Hund et al. 2009a) at the heterotrophic V2 stage and at the autotrophic V4 to V5 stages, respectively.

Growth conditions and experimental design of the growth column experiment

CML444 and SC-Malawi were tested in growth columns $(80 \mathrm{~cm}$ high, $10.5 \mathrm{~cm}$ in diameter) filled with quartz sand. The experiment was designed to test the effect of rooting depth on water uptake (Hund et al. 2009a). Here we present physiological measurements which have not yet been reported. The growth columns were filled with batches of quartz sand (0.08-0.2 mm diameter) mixed with a nutrient solution containing $0.23 \%(\mathrm{v} / \mathrm{v})$ of the liquid fertilizer Wuxal (Aglukon Spezialdünger $\mathrm{GmbH}$, Düsseldorf,

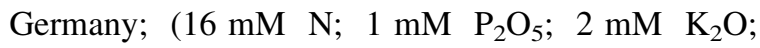
$7.8 \mu \mathrm{M} \mathrm{Fe} ; 6.7 \mu \mathrm{M} \mathrm{Mn} ; 21.3 \mu \mathrm{M} \mathrm{B} ; 2.9 \mu \mathrm{M} \mathrm{Cu}$; $2.2 \mu \mathrm{M} \mathrm{Zn} 1.1 \mu \mathrm{M}$ Mo)). The amount of nutrient solution was adjusted to obtain $100 \%$ (well-watered; WW) and 30\% (water-stressed; WS) of the maximum water-holding capacity $\left(0.228 \mathrm{~m}^{3} \mathrm{~m}^{-3}\right)$ of the substrate. Plants were grown in a growth chamber (PGW36, Conviron, Winnipeg, Canada) at $28 / 24^{\circ} \mathrm{C}$ (day/night), 70/60\% relative humidity (day/night) and a $12 \mathrm{~h}$ photoperiod at $600 \mu \mathrm{mol} \mathrm{cm} \mathrm{cm}^{-2} \mathrm{~s}^{-1}$. All the plants were harvested 30 days after transplanting when they had reached the V5 and V4 stages in WW and WS treatments, respectively.

The experiment consisted of three runs, each set up as a factorial design with two water treatments (WW and WS) and two genotypes. All factorial combinations were assigned to plots of three complete randomized blocks in each of three runs. One plot consisted of one growth column containing one plant. Analysis of variance was computed using PROC MIXED (SAS 8.2). A Block within a run was considered to be random; all other factors were considered to be fixed.

Physiological measurements in growth columns

The operating quantum efficiency of photosystem II photochemistry $\left(\Phi_{\mathrm{PSII}}\right)$, the SLA and the leaf chlorophyll content (SPAD) were assessed. All measurements were conducted in the center of the last fully developed leaf, i.e., leaf 4 for WS and leaf 5 for WW. The third leaf was exposed to the full radiation in the growth chamber at least $20 \mathrm{~min}$ before the measurements, were taken by rotating the pots accordingly. $\Phi_{\text {PSII }}$ was measured using a portable, open-flow gasexchange system LI-6400 (LI-COR, Lincoln, NE, USA) equipped with a 6400-40 leaf chamber fluorometer (LI-COR). The maximum fluorescence in the light-adapted state $\left(\mathrm{F}_{\mathrm{m}}{ }^{\prime}\right)$ was determined by applying a 0.8 -s saturation flash $\left(>8,000 \mathrm{mmol}\right.$ quanta $\left.\mathrm{m}^{-2} \mathrm{~s}^{-1}\right)$. $\Phi_{\text {PSII }}$ was calculated as $\left(\mathrm{F}_{\mathrm{m}}{ }^{\prime}-\mathrm{F}^{\prime}\right) / \mathrm{F}_{\mathrm{m}}{ }^{\prime}$ (Genty et al. 1989). The environmental settings of the LI-6400 were the same as specified by Hund et al. (2009a). The chlorophyll content was measured with a SPAD-502 instrument (Konica Minolta Sensing, Inc., Sakai, Osaka, Japan) by averaging three measurements taken at random locations in the middle of the leaf. 
The area of the fully developed leaves was measured separately with a leaf-area meter (LI3000a, LI-COR, Lincoln, NE, USA); the dry weight of the fully developed leaves was recorded after drying the leaves at $65^{\circ} \mathrm{C}$ for $72 \mathrm{~h}$. The SLA was calculated as the ratio between the area and the weight of the fully developed leaves.

Test of parental lines in growth pouches

In a preliminary study the parental lines CML444 and SC-Malawi (12 plants each) were grown in pouches in order to assess comparability with results obtained in the sand column study. The growth conditions, duration, measurements and harvest were carried out in the same way as in the QTL mapping study described below.

\section{QTL experiment}

Plant material and growth conditions A population of 236 recombinant inbred lines (RILs, F7:S6) of the cross between the two tropical maize inbred lines CML444 and SC-Malawi was phenotyped. Seeds were surface sterilized with $2.5 \% \mathrm{NaOCl}$ solution. Upon germination seeds with equal root lengths were transferred to moistened blue germination blotter (Anchor Paper, St. Paul, MN, USA), $21 \times 30 \mathrm{~cm}$, and covered with opaque plastic foil to form a growth pouch as described by Hund et al. (2009b).

The pouches were placed in containers $(132 \mathrm{~cm}$ long $\times 37 \mathrm{~cm}$ wide $\times 32 \mathrm{~cm}$ high) containing 151 of a modified Hoagland solution $\left(5 \mathrm{mM} \mathrm{KNO}_{3}\right.$,

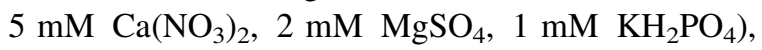
so that the lowest $2 \mathrm{~cm}$ of the pouch were immersed in the nutrient solution. The containers were placed in a growth chamber (PGW36 Conviron, Winnipeg, $\mathrm{MB}$, Canada) at a temperature of $27^{\circ} \mathrm{C}$ at the seed level, a relative humidity of $70 \%$ and a photosynthetically active radiation of $400 \mu \mathrm{mol} \mathrm{s} \mathrm{s}^{-1} \mathrm{~m}^{-2}$; The photoperiod was $12 \mathrm{~h}$. In order to minimize heating due to light radiation, the containers were covered with aluminum-laminated styrofoam, leaving a $2 \mathrm{~cm}$ wide opening at the seedlings position.

Physiological measurements in the growth pouch experiment In the QTL mapping experiment, the quantum efficiency of photosystem II photochemistry $\left(\Phi_{\text {PSII }}\right.$; Genty et al. 1989) and SPAD were measured on the second leaf 10 days after germination (DAG). $\Phi_{\text {PSII }}$ was measured with a PAM-2000 (Walz, Effeltrich, Germany). $\Phi_{\text {PSII }}$ was calculated as $\left(\mathrm{F}_{\mathrm{m}}{ }^{\prime}-\mathrm{F}^{\prime}\right) / \mathrm{F}_{\mathrm{m}}{ }^{\prime}$ (Genty et al. 1989). The chlorophyll content was measured with a SPAD-502 instrument (Konica Minolta Sensing, Inc., Sakai, Osaka, Japan) by averaging three measurements taken at random locations in the middle of the youngest fully developed leaf.

Plants were harvested 11 DAG. At harvest the leaf area (LA) was measured using a Li-3000A instrument (LI-COR Biosciences, Lincoln, NE, USA). The dry weight of shoots (SDW) and roots (RDW) were determined after drying for $72 \mathrm{~h}$ at $65^{\circ} \mathrm{C}$. The SLA was calculated as the ratio of total leaf area to total leaf weight. In order to quantify the effect of seed reserves on plant growth hundred kernel weight (HKW) was measured based on the weight of 50 randomly selected seeds for all maize lines evaluated in the present study.

Experimental design and statistics The experiment was designed as an alpha lattice $(0,1)$ with six independent replications $\left(r_{j}\right), 240$ genotypes $\left(g_{i} ; 236\right.$ RILs and $2 \times 2$ parents) and 12 plots per incomplete block $\left(p_{j k l}\right)$. Overall each genotype was replicated six times. The 20 incomplete blocks $\left(p_{j k l}\right)$ were distributed among five growth containers ( $b_{j k}$; $132 \times 32 \mathrm{~cm})$ in a growth chamber. The replication effects were considered to be fixed, while the genotypes and incomplete blocks nested within containers were considered to be random. The design was chosen to control the spatial variation of environmental conditions in the growth chamber and the variation resulting from handling of the pouches.

Accordingly, the mixed linear model was:

$Y_{i j k l}=\mu+r_{j}+g_{i}+b_{j k}+p_{j k l}+\varepsilon_{i j k l}$

where $Y_{i j k l}$ is the effect of genotype $i$ in the growth chamber run $j(j=1, \ldots, 6)$, growth container $k$ $(k=1, \ldots, 5)$ and incomplete block $l(l=1, \ldots, 20)$; $\mu$ is the overall mean and $\varepsilon$ the residual error.

Analysis of variance was carried out with the $\mathrm{R}$ package ASREML (Butler 2006), and the best linear unbiased predictors (BLUPs), extracted for each genotype-by-block combination, were used as the input values for the QTL mapping. The broad-sense heritability of each treatment was calculated as: 
$h^{2}=\frac{\sigma_{\mathrm{g}}^{2}}{\sigma_{\mathrm{g}}^{2}+\frac{1}{j} \sigma_{\varepsilon}^{2}}$

where $\sigma_{\varepsilon}^{2}$ is the genetic variance, $\sigma_{\varepsilon}^{2}$ is the residual error variance and $j$ is the number of replications. Phenotypic Pearson's correlations between pairs of traits were estimated with the function cor. test () in $\mathrm{R}$ (R Development Core Team 2008). Significant correlations with $0.2 \leq r^{2} \leq 0.5,0.5<r^{2} \leq 0.8$ and $0.8<r^{2}$, were considered weak, moderate and strong, respectively.

\section{QTL analysis}

The QTLs were identified by composite interval mapping (CIM) using QTL cartographer 1.17 (Basten et al. 2002) using the linkage map created by Messmer (2006). The blocking window size was set at $10 \mathrm{cM}$. Co-factors were selected by forward and backward regression with the in and out values set at 0.05 and 0.1 , respectively. The walking speed was $2 \mathrm{cM}$ and the background parameters were set at 5 . QTLs with a LOD-score above 2.6 were considered to be significant $(\alpha=0.05)$.

QTLs for different traits were declared to be coincident (collocated) when their positions with highest LOD scores (peak) were located in the same bin. The collocation was "positive" when the additive effects had the same algebraic sign ( + or $-)$ and "negative" when they had opposite algebraic signs.

\section{Results}

CML444 had greener leaves, independent of culture system and developmental stage

Under well-watered conditions in growth columns, CML444 had 9.9\% higher SPAD values, accompanied by a $29.5 \%$ lower SLA but a similar $\Phi_{\text {PSII }}$ compared to SC-Malawi (Table 1). Under waterstressed conditions, CML444 maintained its higher SPAD values $(19.1 \%)$, but both genotypes had a similar SLA, as it increased in CML444. Furthermore, CML444 could maintain a high $\Phi_{\mathrm{PSII}}$, while the values for SC-Malawi decreased, resulting in $\Phi_{\text {PSII }}$ $27.2 \%$ higher for CML444. Under water-stressed conditions LA decreased by $68 \%$.

Results obtained in the preliminary study at the V2 stage in growth pouches showed that CML444 leaves were $32 \%$ smaller than those of SC-Malawi (Table 2), whereas the $\Phi_{\text {PSII }}$ and SPAD of the former were 19 and $50 \%$ higher, respectively.

Values obtained for SPAD in growth pouches at the V2 stage were comparable to those measured at the V4/V5 stage in soil columns. Higher SPAD values for CML444 than the ones from SC-Malawi were found under both well-watered and water-stressed conditions in columns (Table 1) as well as in growth pouches (Table 2). A higher $\Phi_{\text {PSII }}$ was found for plants in pouches and under water stressed conditions in the growth columns. Higher SLA values were only found under well-watered conditions in the growth columns.
Table 1 Photosynthetic traits measured on two genotypes grown in $80 \mathrm{~cm}$ growth columns under well-watered (WW) and water-stressed (WS) conditions at the V5 stage; quantum efficiency of photosystem II in the light $\left(\Phi_{\mathrm{PSII}}\right)$, specific leaf area of the fully developed leaves two to four (SLA) and leaf greenness (SPAD)

\begin{tabular}{|c|c|c|c|c|c|}
\hline & & $\begin{array}{l}\Phi_{\text {PSII }} \\
\left(\mu \mathrm{mol} \mathrm{m}{ }^{-2} \mathrm{~s}^{-1}\right)\end{array}$ & $\begin{array}{l}\text { SLA } \\
\left(\mathrm{cm}^{2} \mathrm{mg}^{-1}\right)\end{array}$ & SPAD & $\begin{array}{l}\mathrm{LA} \\
\left(\mathrm{cm}^{2}\right)\end{array}$ \\
\hline & Treatment & $* * *$ & NS & $* * *$ & $* * *$ \\
\hline & Genotype & $* * *$ & $* * *$ & $* * *$ & NS \\
\hline & Genotype $\times$ treatment & $* * *$ & $*$ & NS & NS \\
\hline \multirow[t]{2}{*}{ WW } & CML444 & $0.423 \mathrm{~A}$ & $0.0246 b$ & $46.7 \mathrm{ab}$ & $466.99 a$ \\
\hline & SC-Malawi & $0.429 \mathrm{~A}$ & $0.0349 \mathrm{a}$ & $42.1 \mathrm{c}$ & $402.14 \mathrm{a}$ \\
\hline \multirow[t]{2}{*}{ WS } & CML444 & $0.386 \mathrm{~B}$ & $0.0307 \mathrm{a}$ & $42.4 \mathrm{a}$ & $145.1 \mathrm{~b}$ \\
\hline & SC-Malawi & $0.281 \mathrm{C}$ & $0.0313 \mathrm{a}$ & $34.3 b$ & $133.37 b$ \\
\hline
\end{tabular}

Genotype-treatment combinations followed by the same letter are not significantly different

$* P=0.05, * * * P=0.001$ 
Table 2 Average values for the parental lines in the parental comparison study for the following traits measured at the V2 stage

\begin{tabular}{lll}
\hline & CML444 & SC-Malawi \\
\hline$\Phi_{\text {PSII }}\left(\mu \mathrm{mol} \mathrm{m} \mathrm{m}^{-2} \mathrm{~s}^{-1}\right)$ & 0.632 & $0.534^{\mathrm{a}}$ \\
SPAD & 34.4 & $22.8^{\mathrm{a}}$ \\
SLA $\left(\mathrm{cm}^{2} \mathrm{mg}^{-1}\right)$ & 0.499 & $0.510 \mathrm{NS}$ \\
LA $\left(\mathrm{cm}^{2}\right)$ & 18.0 & $26.5^{\mathrm{a}}$ \\
LDW $(\mathrm{mg})$ & 37.5 & $48.0 \mathrm{NS}$ \\
SDW $(\mathrm{mg})$ & 64.9 & $83.4 \mathrm{NS}$ \\
RDW $(\mathrm{mg})$ & 46.1 & $51.1 \mathrm{NS}$ \\
\hline
\end{tabular}

$\Phi_{\text {PSII }}$ quantum efficiency of photosystem II, $S P A D$ leaf chlorophyll content, SLA specific leaf area, $L A$ leaf area, $L D W$ leaf dry weight, $S D W$ shoot dry weight, $L W P$ predawn leaf water potential, $R D W$ root dry weight

${ }^{a}$ Indicates significant differences between CML444 and SCMalawi

However, similar tendencies were observed in the pouches (ns) and under water stress in the growth columns. Therefore, the observations indicate constitutive differences between the two parental lines as far as the SPAD values are concerned.

QTL experiment

Differences between the CML444 and SC-Malawi were not significantly different in the QTL mapping experiment. Moreover trait values measured in the QTL mapping experiment (Table 3) were not significantly different from those in the preliminary study with growth pouches (Table 2). In the QTL mapping experiment population means for SLA (2\%), LA
(18\%), LDW (16\%) and SDW (18\%) were higher than the means of the two parental lines, while population means were lower for $\Phi_{\text {PSII }}(5 \%)$, HKW (3\%) and SPAD (8\%). Indications for transgressive segregation were obtained for all traits, as indicated by lower minimum trait values of the population and higher maximum trait values of the population compared to trait values measured for CML444 and SC-Malawi. The broad sense heritability ranged from 0.61 for SLA to 0.84 for LA. The high broad sense heritability for $\Phi_{\text {PSII }}(76 \%)$ and SPAD $(82 \%)$ indicate the genetic stability of these traits across generations.

\section{Phenotypic correlations}

Hundred kernel weight was weakly correlated with SPAD, SLA and LA, the correlation was moderate with LDW and SDW, highlighting the influence of seed reserves on these traits (Table 4). $\Phi_{\text {PSII }}$ was weakly and negatively correlated with LA, SDW and SLA, indicating that plants with a smaller canopy and thicker leaves have a higher CER per unit leaf area. SPAD showed a weak negative correlation with SLA. A weak positive correlation was found between SPAD and $\Phi_{\text {PSII }}$ as well as between SPAD and LWP.

QTL detected in growth pouches

Twenty-two QTLs were identified for seven traits (Table 5): HKW (five), $\Phi_{\text {PSII }}$ (four), SPAD (three), SDW (three) and SLA (three), LA (two) and LDW (two). Except for SPAD, alleles that increased trait values were derived from both parental lines.

Table 3 Average, minimum (min) and maximum (max) values for the parental lines and the RILs and trait heritability for the following traits in the QTL experiment

\begin{tabular}{|c|c|c|c|c|c|c|c|}
\hline Trait & CML444 & Malawi & Sig & Pop_mean & Min & Max & $h^{2}$ \\
\hline$\Phi_{\mathrm{PSII}}\left(\mu \mathrm{mol} \mathrm{m}{ }^{-2} \mathrm{~s}^{-1}\right)$ & 0.636 & 0.625 & NS & 0.598 & 0.46 & 0.66 & 0.76 \\
\hline SPAD & 27.8 & 23.5 & NS & 23.7 & 13.4 & 32.4 & 0.82 \\
\hline SLA $\left(\mathrm{cm}^{2} \mathrm{mg}^{-1}\right)$ & 0.522 & 0.522 & NS & 0.534 & 0.46 & 0.61 & 0.61 \\
\hline $\mathrm{LA}\left(\mathrm{cm}^{2}\right)$ & 16.4 & 17.9 & NS & 21.3 & 12.6 & 33.6 & 0.84 \\
\hline LDW (mg) & 32.3 & 34.7 & NS & 40.2 & 24.6 & 59.3 & 0.81 \\
\hline SDW (mg) & 48.0 & 55.1 & NS & 62.8 & 39.4 & 94.6 & 0.82 \\
\hline RDW (mg) & 54.8 & 29.2 & NS & 42.5 & 28.8 & 71.1 & 0.87 \\
\hline HKW (g) & 25 & 25.0 & NS & 24.4 & 13.9 & 39.2 & $\mathrm{NA}^{\mathrm{a}}$ \\
\hline
\end{tabular}

$\Phi_{\text {PSII }}$ quantum efficiency of photosystem II, $S P A D$ leaf chlorophyll content, $S L A$ specific leaf area, $L A$ leaf area, $L D W$ leaf dry weight, $S D W$ shoot dry weight, $R D W$ root dry weight, $H K W$ hundred kernel weight

a Not available 
Table 4 Pearson's phenotypic correlation coefficients among traits measured in the RIL population for the following traits

\begin{tabular}{|c|c|c|c|c|c|c|c|c|}
\hline Trait & $\Phi_{\text {PSII }}$ & SPAD & LWP & LA & LDW & SDW & RDW & SLA \\
\hline HKW & $-0.01 \mathrm{NS}$ & $0.36 * * *$ & $0.19 \mathrm{NS}$ & $0.53 * * *$ & $0.58 * * *$ & $0.52 * * *$ & $0.21 *$ & $-0.17 *$ \\
\hline$\Phi_{\text {PSII }}$ & & $0.30 * * *$ & $0.13 \mathrm{NS}$ & $-0.26 * * *$ & $-0.17 *$ & $-0.23 * * *$ & $-0.20 \mathrm{NS}$ & $-0.26 * * *$ \\
\hline SPAD & & & $0.22 *$ & $0.02 \mathrm{NS}$ & $0.10 \mathrm{NS}$ & $0.12 \mathrm{NS}$ & $0.12 \mathrm{NS}$ & $-0.30 * * *$ \\
\hline LWP & & & & $-0.02 \mathrm{NS}$ & $0.09 \mathrm{NS}$ & $0.06 \mathrm{NS}$ & $-0.07 \mathrm{NS}$ & $-0.25^{*}$ \\
\hline LA & & & & & $0.93 \mathrm{NS}$ & $0.77 * * *$ & $0.51 * * *$ & $0.08 \mathrm{NS}$ \\
\hline LDW & & & & & & $0.80 * * *$ & $0.47 * * *$ & $-0.26 * * *$ \\
\hline SDW & & & & & & & $0.35 * * *$ & $-0.16^{*}$ \\
\hline RDW & & & & & & & & $-0.03 \mathrm{NS}$ \\
\hline
\end{tabular}

$\Phi_{\text {PSII }}$ quantum efficiency of photosystem II, $S P A D$ leaf chlorophyll content, $L W P$ predawn leaf water potential, $L A$ leaf area, $L D W$ leaf dry weight, $S D W$ shoot dry weight, $R D W$ root dry weight, $S L A$ specific leaf area

$* P=0.05, * * P=0.01, * * * P=0.001$

Table 5 Genetic characteristics of the QTLs (LOD > 2.6) related to the expression of quantum efficiency of photosystem (SLA), leaf area (LA), leaf dry weight (LDW), shoot dry II $\left(\Phi_{\text {PSII }}\right)$, leaf chlorophyll content (SPAD), specific leaf area weight (SDW), and hundred kernel weight (HKW)

\begin{tabular}{|c|c|c|c|c|c|c|c|}
\hline Trait & Bin & Mark & Peak & Interval & LOD & ADD & PVE \% \\
\hline$\Phi_{\text {PSII }}\left(\mu \mathrm{mol} \mathrm{m} \mathrm{m}^{-2} \mathrm{~s}^{-1}\right)$ & 1.06 & umc1122 & 204 & $185-221$ & 2.72 & 0.009 & 6.9 \\
\hline$\Phi_{\text {PSII }}\left(\mu \mathrm{mol} \mathrm{m}{ }^{-2} \mathrm{~s}^{-1}\right)$ & 2.05 & umc8g & 116 & $90-125$ & 2.97 & 0.008 & 5.2 \\
\hline$\Phi_{\text {PSII }}\left(\mu \mathrm{mol} \mathrm{m}{ }^{-2} \mathrm{~s}^{-1}\right)$ & 7.03 & bnlg 1805 & 82 & $74-95$ & 5.80 & 0.011 & 10.4 \\
\hline$\Phi_{\text {PSII }}\left(\mu \mathrm{mol} \mathrm{m}{ }^{-2} \mathrm{~s}^{-1}\right)$ & 8.06 & umc $48 \mathrm{a}$ & 132 & $118-148$ & 6.39 & -0.012 & 11.9 \\
\hline SPAD & 1.06 & umc1122 & 202 & $183-218$ & 2.65 & 0.855 & 7.9 \\
\hline SPAD & 7.01 & umc1066 & 11 & $1-25$ & 4.84 & 1.02 & 10.7 \\
\hline SPAD & 7.03 & bnlg 155 & 78 & $62-93$ & 5.23 & 1.02 & 11.2 \\
\hline $\operatorname{SLA}\left(\mathrm{cm}^{2} \mathrm{mg}^{-1}\right)$ & 1.08 & umc $166 b$ & 224 & $195-231$ & 5.31 & -0.009 & 10.2 \\
\hline SLA $\left(\mathrm{cm}^{2} \mathrm{mg}^{-1}\right)$ & 1.11 & bnlg 2123 & 369 & $347-370$ & 3.68 & -0.007 & 7.1 \\
\hline SLA $\left(\mathrm{cm}^{2} \mathrm{mg}^{-1}\right)$ & 5.01 & npi409 & 11 & $1-30$ & 5.78 & 0.010 & 13.3 \\
\hline LA $\left(\mathrm{cm}^{2}\right)$ & 5.08 & umc 104b & 244 & $228-244$ & 3.06 & 1.01 & 6.1 \\
\hline LA $\left(\mathrm{cm}^{2}\right)$ & 6.04 & umc65a & 65 & $55-72$ & 3.80 & -1.10 & 7.2 \\
\hline LDW (mg) & 1.08 & umc166b & 222 & $219-231$ & 3.15 & 1.91 & 5.9 \\
\hline LDW (mg) & 6.04 & umc $65 \mathrm{a}$ & 65 & $55-72$ & 3.59 & -2.07 & 6.9 \\
\hline SDW (mg) & 1.02 & bnlg1627 & 64 & $47-76$ & 5.55 & -1.41 & 10.2 \\
\hline SDW (mg) & 1.06 & umc177a & 160 & $148-185$ & 2.87 & -1.01 & 5.5 \\
\hline SDW (mg) & 5.08 & umc104b & 244 & $230-244$ & 4.09 & 1.29 & 9.0 \\
\hline HKW (g) & 1.11 & bnlg2123 & 347 & $330-360$ & 2.93 & 1.16 & 4.9 \\
\hline HKW (g) & 2.04 & umc135 & 102 & $90-114$ & 3.31 & -1.36 & 6.4 \\
\hline HKW (g) & 2.07 & $\operatorname{csu} 154 a$ & 162 & $155-167$ & 2.67 & -1.12 & 4.7 \\
\hline HKW (g) & 6.04 & umc65a & 57 & $43-68$ & 4.18 & -1.38 & 7.1 \\
\hline HKW (g) & 7.01 & umc 1066 & 13 & $1-25$ & 6.45 & 1.91 & 12.7 \\
\hline
\end{tabular}

Chromosome number (Chr), marker number (Marker), marker name (mark), position on the chromosome (bin), position of the peak in cM (Peak), position in centiMorgan on the chromosome, where the LOD-score at the peak decreases by half (Interval), score of the QTL at the peak position (LOD), additive genetic effect of the CML444 allele on trait expression (ADD), percentage of phenotypic variation explained by an individual QTL (PVE)

In accordance with values for the parental lines, the sum of the additive effects of the alleles derived from CML444 generally increased the trait values for
$\Phi_{\text {PSII }}$ and SPAD, while alleles derived from SCMalawi generally increased the trait values for SLA, LA, LDW and SDW. 
Two of the four QTLs identified for $\Phi_{\mathrm{PSII}}$ collocated positively with QTLs for SPAD; in bins 1.06-07 and $7.03(62-95 \mathrm{cM})$ this accounted for 7 and $10 \%$ of the observed phenotypic variance (PVE). Three QTLs for SLA (bins 1.06-07, 1.11 and 5.01) exhibited PVE values of 10,7 and $13 \%$.

Positive collocations were identified for LA and SDW (bin 5.08) and for LA and LDW (bin 6.04) with PVE values ranging from 6 to $8 \%$. Three additional QTLs for LDW (one) and SDW (two) were identified in bins $1.08,1.02$ and 1.06 with PVE values of 5$10 \%$.

Several positive collocations were identified between HKW and SPAD (7.01-02), LA (6.03-04), LDW (6.03-04), $\Phi_{\text {PSII }}$ (2.06-07), suggesting effects of seed reserves on early vigor. Thereby the development of the shoot and the formation of the photosynthetic apparatus are affected.

Collocations with QTLs identified in the field

We compared our QTLs with those detected by Messmer (2006) under field conditions. Seven collocations obtained between QTLs for photosynthesis-related traits (SPAD, SLA and $\Phi_{\mathrm{PSII}}$ ) measured at the seedling stage, with QTLs for traits related to yield formation at the reproductive stage (kernel number, grain yield), suggested a common genetic basis (Fig. 1).

Accordingly, five positive collocations were identified: In bin 5.01 SLA was collocated with kernel number under well watered and water stressed conditions as well as with grain yield under water stressed conditions. In bin 7.03 two QTL for $\Phi_{\text {PSII }}$ and SPAD positively collocated with kernel number under well watered conditions. Two negative collocations were identified in bin 8.06: $\Phi_{\mathrm{PSII}}$ and SPAD were collocated with grain yield and kernel number under well watered conditions. Again collocations obtained for QTLs for photosynthesis-related traits with QTLs for the HKW of the harvested grains emphasized the possible effects of seed reserves on seedling performance (bins 1.06-07, 7.01).

The two most important QTLs for SPAD measured in the field around flowering, i.e., on chromosomes 2 and 10, did not collocate with QTLs identified for

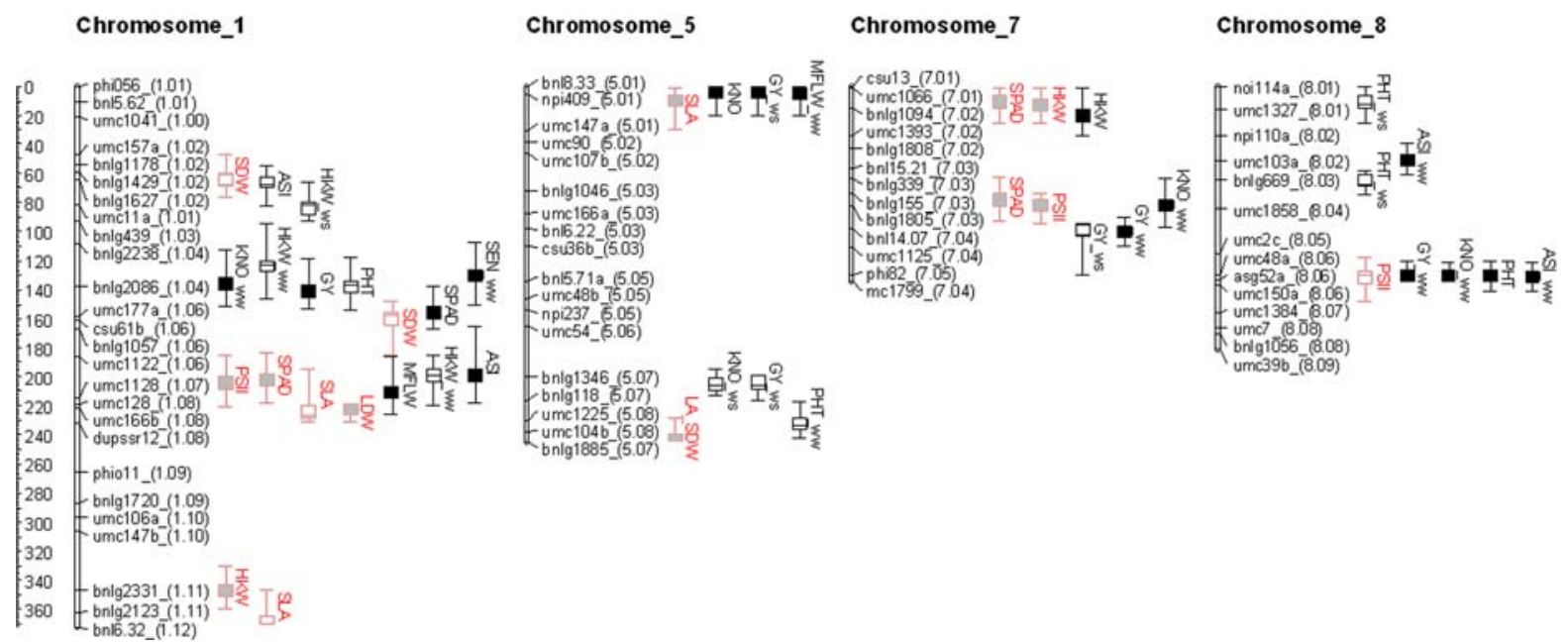

Fig. 1 Collocations of QTLs for quantum efficiency of photosystem II $\left(\Phi_{\mathrm{PSII}}\right)$, leaf chlorophyll content $(S P A D)$, the specific leaf area (SLA), the leaf area $(L A)$, the shoot dry weight $(S D W)$ and the HKW at the seedling stage (grey boxplots), with QTLs for time to male flowering $(M F L W)$, the anthesis silking interval $(A S I)$, plant height $(P H T)$, ear leaf chlorophyll content $(S P A D)$, time to senescence $(S E N)$, kernel number $(K N O)$, HKW and grain yield $(G Y)$ in the same population at the reproductive stage under field conditions (black boxplots) (Messmer 2006; ETH Diss. NO. 16695). Conditions in the field were either water-stressed (WS) or well-watered $(W W)$. QTLs identified under field conditions (black boxplots) not followed by an indicator for the environment were identified under both well-watered and water-stressed conditions. The box of the boxplots indicates the area $\pm 4 \mathrm{cM}$ around the peak of the QTL. Whiskers indicate the confidence interval, i.e., the interval on the chromosome where the LOD at the peak decreased by half. Closed symbols represent trait-increasing alleles derived from CML444 
SPAD in the pouch system. This disproves our hypothesis that leaf greenness of the examined population is controlled by the same set of genes throughout the development of the plant.

Indications of the effects of the photosynthetic machinery on the anthesis silking interval (ASI) were obtained by collocations of QTLs for traits related to photosynthesis at the seedling stage and QTLs for ASI measured under field conditions. In bin (1.07) a QTL for ASI positively collocated with two QTLs for SPAD and $\Phi_{\text {PSII }}$, while it negatively collocated with a QTL for SLA. Another QTL for ASI negatively collocated with a QTL for $\Phi_{\text {PSII }}$ in bin 8.06. The QTLs for the time to male flowering under field conditions in bin 1.06-07 positively collocated with QTLs for SPAD and $\Phi_{\text {PSII }}$ and negatively with a QTL for SLA.

\section{Discussion}

SPAD at the seedling stage is not controlled by the same genes at later stages

CML444 had higher SPAD values than SC-Malawi, irrespective of growing conditions or developmental stage. This strongly supports constitutive differences among the genotypes for leaf chlorophyll content. Accordingly, alleles increasing trait values for SPAD were derived from CML444. Furthermore, Messmer (2006) showed that CML444 had higher SPAD values and lower levels of plant senescence under drought stress at flowering. The observed differences seem to represent the adaptation of CML444 to dry environmental conditions to minimize water loss with a smaller leaf area while maximizing photosynthetic capacity, as indicated by higher values for SPAD and $\Phi_{\text {PSII. }}$ However, while SPAD values were constitutively high, the ability to maintain a high $\Phi_{\text {PSII }}$ under water stress was probably due to the deeper root system of CML444, leading to an increase in water uptake as observed previously (Hund et al. 2009a).

The higher SPAD values of CML444 during several growth stages suggest a common genetic basis across developmental stages. Therefore, it is anticipated that early SPAD values are predictive of SPAD values at later growth stages and even for stay green after flowering. The results of Hirel et al. (2001) support this hypothesis; they found correlations between leaf $\mathrm{N}$ content at the juvenile stage, leaf $\mathrm{N}$ content at anthesis and kernel yield in maize, indicating a general mechanism responsible for the absorption and storage of $\mathrm{N}$.

However, a common genetic basis across developmental stages was not supported in the CML444 × SC-Malawi population; since no collocations were found for QTLs for SPAD measured at the seedling stage (1.06, 7.01 and 7.03) and at flowering (2.04, 10.04 and 1.06).

Apparently, there are no major genes constitutively controlling the expression of leaf chlorophyll content throughout the life cycle of a maize plant. This is not completely surprising, as the genes and physiological pathways involved in the buildup of chlorophyll are likely to differ from those involved in chlorophyll degradation and senescence processes, which influence the chlorophyll content under drought stress at flowering.

Photosynthesis-related traits are under strong genetic control

Two positive collocations for SPAD and $\Phi_{\mathrm{PSII}}$ (bins 1.06 and 7.03) are indicative of pleiotropic effects of these loci on $\Phi_{\text {PSII }}$ and SPAD. This finding is not surprising, as leaf chlorophyll is involved in the formation of the photosynthetic machinery. Although SLA was negatively correlated with $\Phi_{\mathrm{PSII}}$ and SPAD, no corresponding QTLs were detected. The negative correlation is in accordance with findings of Hund et al. (2005), who confirmed negative pleiotropic effects between QTLs for SLA and photosynthesisrelated traits such as SPAD and $\Phi_{\mathrm{PSII}}$ in two mapping populations. Given the negative pleiotropic effects between SLA and photosynthesis, the selection for thinner and larger leaves would decrease the CER per unit leaf area. This is important as SLA has been shown to be one of the most important factors determining early vigor and relative growth rate (Poorter and Van der Werf 1998; Richards et al. 2002). Furthermore, in dry environments, an increased SLA would reduce transpiration efficiency (Sheshshayee et al. 2006). Therefore, knowing which loci affect SLA, SPAD and $\Phi_{\text {PSII }}$ simultaneously, and considering the high heritabilities for $\Phi_{\text {PSII }}(76 \%)$ and SPAD (82\%) and trait consistency at the V2 and V5 stage QTLs identified for SPAD and $\Phi_{\text {PSII }}$ could be used to optimize light harvest by the canopy. 
Seed weight influenced shoot traits

We found that several QTLs for shoot traits coincided with QTLs for seed HKW and that seed HKW correlated with most shoot traits (SLA, SPAD, LA, LDW, SDW). This indicates that shoot traits were affected by nutrient supply, which is in accordance with the fact that the heterotrophic growth lasts until about 9-10 DAG (Bourdu and Grégory 1983; Cooper and Mac Donald 1970; Delèes et al. 1984). Seed size was previously shown to have a positive influence on the seedling vigor of maize (Lopez-Santillan et al. 2005). Furthermore, growth and development of maize depend on seed reserves until the plants pass the 3 leaf stage (Pommel 1990). Seed size might, therefore, be used as a selection criterion for rapid seedling establishment. Thereby the performance of seedlings could be improved. The present data does not explain why heavier seeds resulted in thicker and greener leaves, as indicated by lower SLA and larger SPAD values.

\section{SLA improves early vigor}

We found three QTLs for SLA explaining a high proportion of phenotypic variance observed at a heritability of $61 \%$. By selecting for high SLA, good early vigor, rapid establishment and thus a good performance in the field could be attained. SLA was suggested to be a suitable trait for the selection of plants with good early vigor (Rebetzke et al. 2004), as SLA enables the plant to close the leaf canopy at minimal carbon expenses. Early vigor of a cereal crop is in turn associated with improvements in water use efficiency (Richards and Townleysmith 1987). As a result of early vigor and improved water use efficiency, plants form a larger biomass and a higher grain yield (Fischer 1979). However, it should be taken into account that under-drought stress, a high SLA could result in greater water losses due to the larger leaf area, which is exposed to the surrounding air, resulting in lower transpiration efficiency (Sheshshayee et al. 2006).

Collocations with QTLs for flowering trait, grain yield and plant height

The relevance of traits related to photosynthesis at the seedling stage $\left(\Phi_{\mathrm{PSII}}\right.$, SLA, SPAD) for yield formation in the field (kernel number and grain yield) is indicated by the positive collocation of five of seven identified collocations between photosynthesis related traits at the seedling stage and traits involved in yield formation. Traits related to photosynthesis are crucial for high early vigor, rapid canopy closure and rapid plant establishment (Richards 2000). A well-established plant subsequently has positive effects on kernel weight and kernel number due to a high photosynthetic capacity (Paponov et al. 2005), SLA (Fischer 1979) and leaf chlorophyll content (Wang et al. 1999).

Considering the strong genetic control of $\Phi_{\mathrm{PSII}}$, SPAD and SLA (as described above) collocations for QTLs of these traits with QTLs for grain yield and kernel number, QTLs identified here could be used to improve plant performance at the seedling stage resulting in a higher kernel number and grain yield at the seedling stage.

Collocations between QTLs for traits related to photosynthesis at the seedling stage and QTLs for time to male flowering and for the ASI in the field, indicate the influence of traits related to photosynthesis on general plant vigor, as influenced by the allocation of assimilates. Accordingly, the photosynthetic activity would influence the initiation of silk growth (Hashemidezfouli and Herbert 1992) and would thereby determine the interval between anthesis and silking.

Collocations with QTLs identified in other studies

We identified several QTLs, which were also detected putatively in other studies. A QTL for SPAD and $\Phi_{\text {PSII }}$ in bin 1.06 collocated with a QTL for SPAD in the ETH-DL3 x ETH-DH7 population measured at the second leaf stage at $15^{\circ} \mathrm{C}$ (Jompuk et al. 2005). Furthermore, a collocation for $\Phi_{\text {PSII }}$ was identified in bin 2.05 in the same population at the seedling stage. The observed collocations strongly suggest that the QTLs for SPAD (bins 1.06) and $\Phi_{\text {PSII }}$ (bins 1.06, 2.05) are relevant to photosynthesis and leaf chlorophyll content as they map to the same position in two populations at the same developmental stage.

A candidate gene affecting both SPAD and $\Phi_{\text {PSII }}$ in bin 1.06 is $h c f 50$ (high chlorophyll fluorescence; Miles et al. 1979; Table 6). It primarily affects the formation of the thylakoid membrane core complex of photosystem I. Accordingly, Miller (1980) showed that the thylakoid membrane of the hcf50 mutant lacked two polypeptide bands associated with 
Table 6 Position of potential candidate genes in relation to the QTLs detected in the present study and to common SSR markers from the CML444 $\times$ SC-Malawi population and from the Pioneer composite 1999 map

\begin{tabular}{cll}
\hline Marker/Gene/QTL & Position $(\mathrm{cM})$ & \\
\cline { 2 - 3 } & CIMMYT-population & Pioneer \\
\hline Chromosome 1 & & \\
hcf50 & - & 148 \\
Bnlg1025 & - & 147.7 \\
QTL SPAD/Ф & $183-221$ & \\
umc1122 & 186 & 151 \\
umc1128 & 214 & - \\
Chromosome 2 & & 79.9 \\
hcf106 & - & 78 \\
bnlg1818 & - & \\
QTL $\Phi_{\text {PSII }}$ & $90-125$ & 102 \\
umc8 g & 114 & - \\
csu54a & 119 & \\
\hline
\end{tabular}

photosystem I. Furthermore, they showed that the absence of these two polypeptides was associated with a measurable decline in the particle diameter of the unstacked protoplasmic fracture face. As a result, changes in the activity of photosystem I $(-80 \%)$, photosystem II (-“somewhat”), ATP-synthesis (-80\%) and $\mathrm{CO}_{2}$ fixation (-95\%; Miles 1980; Miles and Metz 1985) were observed.

Fracheboud et al. (2004) suggested that the QTL in bin 2.05 harbored a gene involved in the formation of a chlorophyll fluorescence protein, which was responsible for cold tolerance. A possible candidate gene at this locus, affecting photosystem II, is hcflo6 (high chlorophyll fluorescence; Martienssen et al. 1990; Table 6). hcf106 contains a single nuclear mutation that prevents the normal assembly of photosynthetic electron complexes and causes aberrant thylakoid membrane organization (Barkan et al. 1986). The presence of $h c f 50$ and $h c f 106$ at these loci would strengthen the importance of these loci for the genetic control of $\Phi_{\text {PSII }}$ and SPAD (1.06) in two different populations.

\section{Conclusion}

CML444 constitutively had a higher leaf chlorophyll content than SC-Malawi. CML444 also had a lower leaf area at the V2 stage and a higher quantum efficiency of photosystem II at the V2 stage and under water-stressed conditions at the V5 stage.

Knowing which loci affect SLA, SPAD and $\Phi_{\text {PSII }}$ could aid in the optimization of light harvest by the canopy. Collocations between QTLs of traits related to photosynthesis $\left(\Phi_{\mathrm{PSII}}, \mathrm{SPAD}\right.$ and SLA) and QTLs for kernel number, HKW and grain yield (bins 1.0607, 5.01, 7.01, 7.03, 8.05) under field conditions (Messmer 2006) suggest pleiotropic effects of these loci. Based on the obtained findings linkage cannot be ruled out.

The genetic control of SPAD does not seem to be the same at the seedling and at the reproductive stage. We furthermore identified QTLs for $\Phi_{\text {PSII }}$ (1.06 and 2.05) and SPAD (1.06) across populations. Possible candidate genes at these loci are $h c f 50$ and $h c f 106$. $h c f 50$ is known to affect the formation of the thylakoid membrane core complex of photosystem I, while $h c f 106$ is involved in the organization of the thylakoid membrane.

Considering the importance of $\Phi_{\text {PSII }}$, SPAD and SLA for rapid plant establishment and putative influence on later performance of the plant, information gained here could be used to improve early vigor and plant establishment.

Acknowledgments The authors would like to thank Yunbi $\mathrm{Xu}$ for supplying the mapping population, Susanne Hochmann and David Brändli for technical assistance and Jann Röder for programming the scanning software.

\section{References}

Arunyanark A, Jogloy S, Akkasaeng C, Vorasoot N, Kesmala T, Rao RCN, Wright GC, Patanothai A (2008) Chlorophyll stability is an indicator of drought tolerance in peanut. J Agron Crop Sci 194:113-125

Barkan A, Miles D, Taylor WC (1986) Chloroplast geneexpression in nuclear, photosynthetic mutants of maize. EMBO J 5:1421-1427

Basten CJ, Weir BS, Zing ZB (2002) QTL CARTOGRAPHER: a reference manual and tutorial for QTL mapping. Department of Statistics, North Carolina State University, USA

Bourdu R, Grégory N (1983) Etude comparée du début de la croissance chez divers génotypes de maïs. Agronomie 3:761-770

Butler D (2006) asreml: asreml() fits the linear mixed mode. R package version 2.00

Cooper CS, Mac Donald PW (1970) Energetics of early seeling growth in corn (Zea mays L.). Crop Sci 10:136-139 
Earl HJ, Tollenaar M (1997) Maize leaf absorptance of photosynthetically active radiation and its estimation using a chlorophyll meter. Crop Sci 37:436-440

Fischer RA (1979) Growth and water limitation to dryland wheat yield in Australia-physiological framework. J Austr Inst Agric Sci 45:83-94

Fracheboud Y, Ribaut JM, Vargas M, Messmer R, Stamp P (2002) Identification of quantitative trait loci for coldtolerance of photosynthesis in maize (Zea mays L.). J Exp Bot 53:1967-1977

Fracheboud Y, Jompuk C, Ribaut JM, Stamp P, Leipner J (2004) Genetic analysis of cold-tolerance of photosynthesis in maize. Plant Mol Biol 56:241-253

Genty B, Briantais J-M, Baker NR (1989) The relationship between the quantum yield of photosynthetic electron transport and quenching of chlorophyll fluorescence. Biochim Biophys Acta 990:87-92

Hashemidezfouli A, Herbert SJ (1992) Intensifying plantdensity response of corn with artificial shade. Agron $\mathbf{J}$ 84:547-551

Hirel B, Bertin P, Quillere I, Bourdoncle W, Attagnant C, Dellay C, Gouy A, Cadiou S, Retailliau C, Falque M, Gallais A (2001) Towards a better understanding of the genetic and physiological basis for nitrogen use efficiency in maize. Plant Physiol 125:1258-1270

Hund A, Fracheboud Y, Soldati A, Frascaroli E, Salvi S, Stamp P (2004) QTL controlling root and shoot traits of maize seedlings under cold stress. Theor Appl Genet 109:618-629

Hund A, Frascaroli E, Leipner J, Jompuk C, Stamp P, Fracheboud Y (2005) Cold tolerance of the photosynthetic apparatus: pleiotropic relationship between photosynthetic performance and specific leaf area of maize seedlings. Mol Breed 16:321-331

Hund A, Richner W, Soldati A, Fracheboud Y, Stamp P (2007) Root morphology and photosynthetic performance of maize inbred lines at low temperature. Eur J Agron 27:5261

Hund A, Ruta N, Liedgens M (2009a) Rooting depth and water use efficiency of tropical maize inbred lines, differing in drought tolerance. Plant Soil 318:311-325

Hund A, Trachsel S, Stamp P (2009b) Development of a phenotyping platform for the non-invasive measurement of early root growth. Plant Soil (in press)

Jompuk C, Fracheboud Y, Stamp P, Leipner J (2005) Mapping of quantitative trait loci associated with chilling tolerance in maize (Zea mays L.) seedlings grown under field conditions. J Exp Bot 56:1153-1163

Kalapos T, vandenBoogaard R, Lambers H (1996) Effect of soil drying on growth, biomass allocation and leaf gas exchange of two annual grass species. Plant Soil 185:137-149

Lopez-Santillan JA, Ortiz-Cereceres J, Del Carmen MendozaCastillo M, de los Santos GG, Martinez-Garza A (2005) Influence of the weight of the embryo and endosperm on the initial post-emergent development of maize seedlings. Phyton (Buenos Aires) 2005:155-160

Martienssen R, Barkan A, Taylor WC, Freeling M (1990) Somatically heritable switches in the DNA modification of mu-transposable elements monitored with a suppressible mutant in maize. Genes Dev 4:331-343

Messmer R (2006) The genetic dissection of key factors involved in the drought tolerance of tropical maize (Zea mays L.). Diss. ETH No. 16695, Zurich, Switzerland. http://e-collection.ethbib.ethz.ch/show?type=diss\&nr=16 695

Miles D (1980) Mutants of higher plants maize Zea mays. In: San Pietro A (ed) Methods in enzymology, vol 69 part C photosynthesis and nitrogen fixation $\mathrm{Xxv}+894 \mathrm{p}$, Academic Press, New York, NY, USA; London, England, Illus:P3-23

Miles D, Metz JG (1985) The role of nuclear genes of maize Zea-Mays in chloroplast development. In: Freeling M (ed) UCLA (University of California Los Angeles) Symposia on molecular and cellular biology new series, vol 35 plant genetics; Third Annual Arco Plant Cell Research InstituteUCLA Symposium on Plant Biology, Keystone, CO, USA, Apr 13-19, 1985 Xxvi + 861p Alan R Liss, Inc: New York, NY, USA Illus:585-598

Miles CD, Markwell JP, Thornber JP (1979) Effect of nuclear mutation in maize on photosynthetic activity and content of chlorophyll-protein complexes. Plant Physiol 64:690694

Miller KR (1980) A chloroplast membrane lacking photosystem-I-changes in unstacked membrane regions. Biochim BiophyS Acta 592:143-152

Paponov IA, Sambo P, Erley GSA, Presterl T, Geiger HH, Engels C (2005) Grain yield and kernel weight of two maize genotypes differing in nitrogen use efficiency at various levels of nitrogen and carbohydrate availability during flowering and grain filling. Plant Soil 272:111-123

Piekielek WP, Fox RH (1992) Use of a chlorophyll meter to predict sidedress nitrogen requirements for maize. Agron J 84:59-65

Pommel B (1990) Effects of seed weight and sowing depth on growth and development of maize seedlings. Agronomie 10:699-708

Poorter H, Van der Werf A (1998) Is inherent variation in RGR determined by LAR at low irradiance and by NAR at high irradiance? A review of herbaceous species. In: Lambers H, Poorter H, Van Vuuren MMI (eds) Inherent variation in plant growth physiological mechanisms and ecological consequences. Backhuys Publishers, Leiden, pp 309-332

Rawson HM, Gardner PA, Long MJ (1987) Sources of variation in specific leaf-area in wheat grown at high-temperature. Aust J Plant Physiol 14:287-298

Rebetzke GJ, Botwright TL, Moore CS, Richards RA, Condon AG (2004) Genotypic variation in specific leaf area for genetic improvement of early vigour in wheat. Field Crops Res 88:179-189

Ribaut JM, Betràn FJ, Monneveux P, Setter T (2008) Drought tolerance in maize. In: Hake SC, Bennetzen JL (eds) Hand book of maize: its biology, Springer, Netherlands, pp 311-344 (in press)

Richards RA (2000) Selectable traits to increase crop photosynthesis and yield of grain crops. J Exp Bot 51:447-458

Richards RA, Townleysmith TF (1987) Variation in leaf-area development and its effect on water-use, yield and harvest index of droughted wheat. Aust J Agric Res 38:983-992

Richards RA, Rebetzke GJ, Condon AG, van Herwaarden AF (2002) Breeding opportunities for increasing the efficiency of water use and crop yield in temperate cereals. Crop Sci 42:111-121 
Sarker AM, Rahman MS, Paul NK (1999) Effect of soil moisture on relative leaf water content, chlorophyll, proline and sugar accumulation in wheat. J Agron Crop Sci 183:225-229

Sheshshayee MS, Bindumadhava H, Rachaputi NR, Prasad TG, Udayakumar M, Wright GC, Nigam SN (2006) Leaf chlorophyll concentration relates to transpiration efficiency in peanut. Ann Appl Biol 148:7-15

R Development Core Team (2008) R: a language and environment for statistical computing. $\mathrm{R}$ foundation for statistical computing. In: Computing RFfS (ed), Vienna, Austria
Thomas H, Howarth CJ (2000) Five ways to stay green. J Exp Bot 51:329-337

Wang GL, Kang MS, Moreno O (1999) Genetic analyses of grain-filling rate and duration in maize. Field Crops Res 61:211-222

Wright GC, Hammer GL (1994) Distribution of nitrogen and radiation use efficiency in peanut canopies. Aust J Agric Res 45:565-574

Xu W, Rosenow DT, Nguyen HT (2000) Stay green trait in grain sorghum: relationship between visual rating and leaf chlorophyll concentration. Plant Breed 119:365-367 